\title{
Certified Infertility Nurses' Perceptions and Practice on Male Infertility Nursing and Related Factors
}

\author{
Akiko Mori' ${ }^{1}$ Kyoko Asazawa ${ }^{2}$, Ruriko Hoshi ${ }^{3}$, Yasushi Yumura ${ }^{4}$ \\ ${ }^{1}$ Department of Midwifery and Women's Health, Graduate School of Nursing Science, St. Luke’s International University, Tokyo, \\ Japan \\ ${ }^{2}$ Department of Nursing, Tokyo Healthcare University, Tokyo, Japan \\ ${ }^{3}$ Nursing Department, Yokohama City University, Medical Center, Yokohama, Japan \\ ${ }^{4}$ Reproduction Center, Yokohama City University, Medical Center, Yokohama, Japan \\ Email: akiko-mori@slcn.ac.jp
}

How to cite this paper: Mori, A., Asazawa, K., Hoshi, R. and Yumura, Y. (2018) Certified Infertility Nurses' Perceptions and Practice on Male Infertility Nursing and Related Factors. Open Journal of Nursing, 8, 1-13.

https://doi.org/10.4236/ojn.2018.81001

Received: December 5, 2017

Accepted: January 13, 2018

Published: January 16, 2018

Copyright () 2018 by authors and Scientific Research Publishing Inc. This work is licensed under the Creative Commons Attribution International License (CC BY 4.0).

http://creativecommons.org/licenses/by/4.0/

\begin{abstract}
Purpose: The aims of this study were to clarify the complaints and concerns expressed by couples that included a partner with male infertility, certified infertility nurses' nursing practice and perceptions of nursing for these couples, and factors related to these perceptions and practices. Methods: A quantitative cross-sectional study was conducted. Prospective participants were sent an anonymous self-administered questionnaire containing items pertaining to the complaints and concerns expressed by couples that included a partner with male infertility, and nursing practice and perceptions of nursing for these couples. Results: In total, 133 questionnaires were distributed, 74 responses were received, and 69 of these responses were valid. Couples' complaints and concerns consisted of a three-factor structure comprising psychological burden, lack of knowledge and information, and problems with partners. Nurses reported that the complaints and concerns of couples that included a partner with male infertility differed between male and female partners. Factors related to nursing practice and nurses' perceptions of nursing were identified. Conclusions: Participants felt that psychological burden and problems were more serious for female partners than they were for male partners, and concern regarding the physical health of the partner receiving treatment was greater in male partners than it was in female partners.
\end{abstract}

\section{Keywords}

Professional Practice, Fertility Nurse, Male Infertility 


\section{Introduction}

In Japan, couples faced with infertility are often treated within the framework of obstetrics and gynecology, and there are very few medical institutions in which patients undergo consultations with specialists, even for cases involving male factor infertility. One reason for this is that both medical professionals and patients hold old-fashioned perceptions concerning infertility treatment, whereby male and female partners play equal roles. In addition, there is a shortage of specialists in reproductive medicine who treat male infertility.

The prevalence of male factor infertility, as noted in the specialist literature, is between $30 \%$ and $40 \%$ or $32.7 \%$ according to Japanese studies and approximately $50 \%$ according to studies conducted in other countries [1]. Nachtigall et al. [2] reported that men with male factor infertility exhibited stronger negative emotions during infertility treatment relative to those observed in men without male factor infertility. Moreover, Beutel et al. [3] reported that, in men receiving treatment via assisted reproductive technology (ART), depression was more common in those with male factor infertility than it was in those without male factor infertility.

Few studies have been conducted to examine nurses' contributions to treatment for male infertility patients. Ozawa et al. [4] showed that nurses felt awkward and found it difficult to discuss sex-related matters with male infertility patients. Certified infertility nurses are trained to provide essential information to couples facing infertility, including men, to ensure that they understand their circumstances accurately, and assist them in making decisions regarding treatment. Nurses' roles in the field of infertility nursing include practice, instruction, and consultation, and their confidence has been reported to increase with clinical experience [5]. However, no studies have been conducted to examine the complaints and concerns that clients with male infertility discuss with certified infertility nurses during infertility treatment or specialist consultation. Moreover, certified infertility nurses' perceptions of nursing practice and related factors for couples that include a partner with male infertility have not been clarified.

In light of these points, the study sought to elucidate the current status of male infertility nursing via examination of the work of certified infertility nurses, who encounter numerous couples in specialist infertility clinics and consultations.

In addition, the study aimed to clarify the complaints and concerns expressed by couples that included a partner with male factor infertility, certified infertility nurses' nursing practice and perceptions of nursing for these couples, and factors related to these perceptions and practices.

\section{Materials and Methods}

\subsection{Participants}

Prospective participants included 133 Japanese certified infertility nurses.

The inclusion criteria were: 1) certified infertility nurses; 2) obtained contact information from a list of certified nurses maintained by the Japanese Nursing 
Association; 3) learned male infertility nursing in the educational program; and 4) fluent in Japanese. The exclusion criteria were not working as a nurse.

\subsection{Definition of Terms}

1) Couple with male infertility: Couple that includes a partner with male factor infertility

2) Client: The partner with male factor infertility, or the consulter

3) Partner: The client's female partner

4) Certified infertility nurse: A nurse certified in infertility nursing by Japanese Nursing Association

\subsection{Procedure}

A quantitative cross-sectional study design was used. Participation requests and anonymous self-administered questionnaires were sent to prospective participants via mail, and responses were returned individually between December 2015 and January 2016.

\subsection{Questionnaire}

The questionnaire consisted of nurses' background, environment, and their perceptions and practice of nursing for the infertile couples with male factor. The questionnaire items pertaining to couples' complaints and concerns and nursing practice and perceptions of nursing for these couples were created by a reproductive medicine specialist certified by the Japan Society for Reproductive Medicine and three specialists in reproductive health nursing. Some certified nurses were asked to check the surface validity.

\subsubsection{Personal Attributes}

Participants' personal attributes included age, years of nursing experience, place of employment, and qualifications. Participants were also asked about the frequency with which they saw clients, opportunities for physical care, the number of consultations provided, and their clients.

\subsubsection{Complaints and Concerns Expressed by Clients and Partners}

A total of 30 items were created to examine the complaints and concerns expressed by couples that included a partner with male factor infertility, reported by certified infertility nurses; of these, 15 items pertained to clients, and 15 items pertained to their partners. Responses were provided using a five-point scale, and scores ranged from 15 to 75 , with higher scores indicating the expression of stronger concerns, as reported by the nurses.

\subsubsection{Perceptions of Nursing for Couples That Included a Partner with Male Factor Infertility}

Seventeen items were used to examine certified infertility nurses' perceptions of nursing for couples that included a partner with male infertility. Responses were provided using a five-point scale, and scores ranged from 17 to 85 , with higher 
scores indicating more consciousness of nursing role for couples that included a partner with male infertility.

\subsubsection{Nursing Practices for Couples That Included a Partner with Male Infertility}

Seventeen items were used to examine nursing practice for couples that included a partner with male infertility. Responses were provided using a five-point scale, and scores ranged from 17 to 85 , with higher scores indicating that nurses provided more nursing care to couples that included a partner with male infertility.

\subsection{Data Analysis}

SPSS 23.0 J for Windows statistical software was used to perform quantitative analyses, with the significance level set at $p<0.05$. Descriptive statistics were calculated, and factor analysis, reliability analysis, and Wilcoxon signed-rank tests were performed. A factor structure consisting of three scales, 1) clients' complaints and concerns, 2) perceptions of nursing for couples that include a partner with male factor infertility, and 3) nursing practice for couples that include a partner with male factor infertility, was assessed and tested for reliability and validity. Factor analysis was performed for the 15 items pertaining to clients' complaints and concerns, as reported by the participants. Total scores were also calculated for the three scales. Frequency distributions were measured for each of the 30 items regarding clients' and partners' complaints and concerns, as reported by the participants, using frequency tables, and the disparity between couples was assessed. The differences between total scores for complaints and concerns for clients and their partners were examined using $t$ tests. Wilcoxon signed-rank tests were performed to examine the differences between clients and partners. Differences in perceptions of nursing and nursing practice according to nurses' attributes were examined using $t$ tests and one-way analyses of variance (ANOVAs); unpaired $t$ tests were performed for cases involving two groups of independent variables, and ANOVAs were performed for cases involving three or more independent variables. When variance was assumed to be equal, Tukey's method was used to perform multiple comparisons. Associations between scores for nursing practice and perceptions of nursing for couples that included a partner with male factor infertility and years of nursing experience and years of infertility nursing experience were examined using Pearson's correlation coefficients.

\subsection{Ethical Considerations}

Participants were provided with oral and written explanations regarding the study purpose and method and assured that participation was voluntary and could be withdrawn at any time, anonymity would be maintained, privacy would be protected, they would suffer no disadvantages, results would not be used for any purposes other than those intended, and data would be retained for three years after publication and then shredded and discarded. The receipt of a com- 
pleted questionnaire was considered to indicate consent. The study protocol was approved by the Yokohama City University Ethics Committee (approval No. D1510026).

\section{Results}

A total of 133 questionnaires were distributed, 74 responses were received (response rate: 55.6\%), and 69 responses were valid (valid response rate: 93.2\%).

\subsection{Participants' Attributes}

The results regarding participants' attributes are shown in Table 1 and Table 2. The mean durations of participants' nursing experience and infertility nursing experience were 21 years and 7 months and 12 years and 2 months, respectively. Most were qualified midwives (50.7\%) and aged between 45 and 54 years (58.0\%). In addition, most nurses worked at a clinic (47.8\%), infertility department, or reproductive medicine center (58.0\%), or as a full-time outpatient clinic nurse (71.0\%). Treatment was provided by part-time reproductive medicine specialists in urology departments and full-time urologists who were not specialists in reproductive medicine at $27.5 \%$ and $23.2 \%$ of the facilities at which the nurses worked, respectively. In addition, $47.8 \%$ of participants had opportunities to talk to a urologist while $46.4 \%$ lacked such opportunities, and most participants had taken classes in the provision of nursing care for male infertility patients (87.0\%). In addition, $59.4 \%, 27.5 \%$, and $5.8 \%$ of participants had participated in consultations with clients' partners alone, couples, and clients alone, respectively, during the preceding 12 months.

\subsection{Variable Factor Structure}

The results of the factor analysis of the 15 items pertaining to clients' complaints and concerns revealed a three-factor structure. The first, second, and third factors were named "psychological burden", "lack of knowledge and information", and "problems with the partner", respectively. The factor loadings ranged from 0.31 to 0.83 . Cronbach's $a$ s were 0.87 for the overall scale and ranged from 0.71 to 0.82 for the individual subscales.

The 17 items regarding perceptions of nursing for couples that included a partner with male infertility showed a three-factor structure with factor loadings ranging from 0.45 to 0.92 and an overall Cronbach's $\alpha$ of 0.85 . The 17 items regarding nursing practice for couples that included a partner with male infertility showed a four-factor structure with factor loadings ranging from 0.43 to 0.99 and an overall Cronbach's $\alpha$ of 0.87 . This confirmed the validity and reliability of the three scales.

\subsection{Clients' and Partners' Complaints and Concerns}

The results regarding clients' and partners' complaints and concerns are shown in Figure 1. Shapiro-Wilk tests for the total scores for each of the clients' and partners' complaints and concerns reported by the participants, nursing practice, 
Table 1. Participant attributes $(\mathrm{N}=69)$.

\begin{tabular}{|c|c|c|c|}
\hline \multicolumn{2}{|r|}{ Item } & \multicolumn{2}{|c|}{ Mean (range) } \\
\hline \multirow[t]{2}{*}{ Nursing experience } & Mean length & \multirow{2}{*}{\multicolumn{2}{|c|}{$\begin{array}{c}21 \text { years and } 7 \text { months } \\
\text { (6 years, } 2 \text { months to } \\
41 \text { years, } 9 \text { months) }\end{array}$}} \\
\hline & (Range) & & \\
\hline \multirow[t]{3}{*}{ Infertility nursing experience } & Mean length & \multirow{2}{*}{\multicolumn{2}{|c|}{$\begin{array}{c}12 \text { years and } 2 \text { months } \\
\text { (4 years, } 6 \text { months to } \\
29 \text { years, } 8 \text { months) }\end{array}$}} \\
\hline & \multirow[t]{2}{*}{ (Range) } & & \\
\hline & & $\mathrm{n}$ & $\%$ \\
\hline \multirow[t]{5}{*}{ Nursing qualifications } & Nurse, midwife & 35 & 50.7 \\
\hline & Nurse & 26 & 37.7 \\
\hline & Nurse, public health nurse & 4 & 5.8 \\
\hline & Nurse, midwife, public health nurse & 3 & 4.3 \\
\hline & No response & 1 & 1.4 \\
\hline \multirow[t]{5}{*}{ Age } & 45 to 54 years & 40 & 58.0 \\
\hline & 35 to 44 years & 20 & 29.0 \\
\hline & 25 to 34 years & 4 & 5.8 \\
\hline & 55 to 64 years & 4 & 5.8 \\
\hline & No response & 1 & 1.4 \\
\hline \multirow[t]{5}{*}{ Facility of employment } & Clinic & 33 & 47.8 \\
\hline & General hospital & 17 & 24.6 \\
\hline & University hospital & 16 & 23.2 \\
\hline & Other institution & 2 & 2.9 \\
\hline & No response & 1 & 1.4 \\
\hline \multirow[t]{4}{*}{ Place of employment } & Infertility department or reproductive medicine center & 40 & 58.0 \\
\hline & Obstetrics and gynecology & 22 & 31.9 \\
\hline & Other department & 3 & 4.3 \\
\hline & No response & 4 & 5.8 \\
\hline \multirow[t]{5}{*}{ Position } & Full-time outpatient nurse & 49 & 71.0 \\
\hline & Outpatient and ward nurse & 10 & 14.5 \\
\hline & Full-time ward nurse & 6 & 8.7 \\
\hline & Other & 3 & 4.3 \\
\hline & No response & 1 & 1.4 \\
\hline \multirow[t]{7}{*}{ Treatment system } & Part-time reproductive medicine specialist in the urology department & 19 & 27.5 \\
\hline & Full-time urologist who is not a reproductive medicine specialist & 16 & 23.2 \\
\hline & No urologist, reference given & 13 & 18.8 \\
\hline & No urologist, only a gynecologist & 7 & 10.1 \\
\hline & Full-time reproductive medicine specialist in the urology department & 5 & 7.2 \\
\hline & Part-time urologist who is not a reproductive medicine specialist & 4 & 5.8 \\
\hline & No response & 5 & 7.2 \\
\hline \multirow[t]{3}{*}{ Opportunities to talk to a urologist } & Yes & 33 & 47.8 \\
\hline & No & 32 & 46.4 \\
\hline & No response & 4 & 5.8 \\
\hline \multirow{4}{*}{$\begin{array}{l}\text { Took classes on nursing care } \\
\text { for male infertility patients }\end{array}$} & Yes & 60 & 87.0 \\
\hline & No & 4 & 5.8 \\
\hline & Not sure & 4 & 5.8 \\
\hline & No response & 1 & 1.4 \\
\hline
\end{tabular}




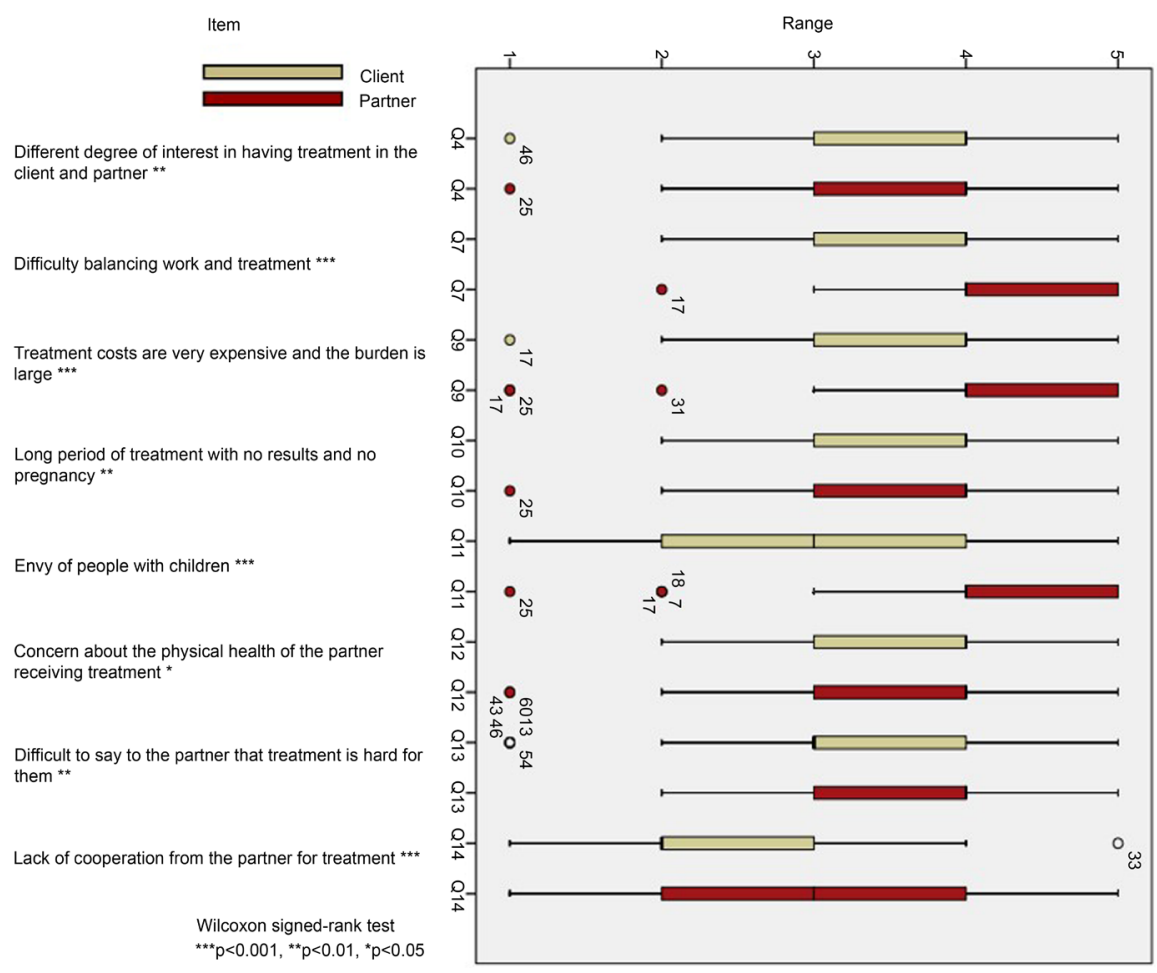

Figure 1. Complaints and concerns expressed by male infertility clients and their partners $(N=69)$.

Table 2. Participants' current circumstances in providing nursing for male infertility patients $(\mathrm{N}=69)$.

\begin{tabular}{|c|c|c|c|}
\hline \multicolumn{2}{|c|}{ Item } & \multirow{2}{*}{$\begin{array}{c}\mathrm{n} \\
33\end{array}$} & \multirow{2}{*}{$\begin{array}{c}\% \\
47.8\end{array}$} \\
\hline Meeting with male patients & Occasionally & & \\
\hline & Almost everyday & 20 & 29.0 \\
\hline & Very rarely & 14 & 20.3 \\
\hline & No response & 2 & 2.9 \\
\hline \multirow[t]{4}{*}{ Opportunities to provide physical care } & No & 40 & 58.0 \\
\hline & Yes & 26 & 37.7 \\
\hline & Not sure & 2 & 2.9 \\
\hline & No response & 1 & 1.4 \\
\hline \multirow[t]{7}{*}{ No. of consultations } & 1 to 10 & 31 & 44.9 \\
\hline & 21 or more & 20 & 29.0 \\
\hline & 11 to 20 & 14 & 20.3 \\
\hline & 0 & 2 & 2.9 \\
\hline & No response & 2 & 2.9 \\
\hline & Partner & 41 & 59.4 \\
\hline & Couple & 19 & 27.5 \\
\hline \multirow[t]{3}{*}{ Consulter } & Client & 4 & 5.8 \\
\hline & Other & 2 & 2.9 \\
\hline & No response & 3 & 4.3 \\
\hline \multirow[t]{5}{*}{ Location of consultation (multiple responses allowed) } & Outpatient visit & 55 & \\
\hline & Consultation day & 18 & \\
\hline & Class & 5 & \\
\hline & Infertility Specialist Consultation Center & 5 & \\
\hline & Bedside in a hospital ward, etc. & 3 & \\
\hline
\end{tabular}


and perceptions of nursing were normally distributed; therefore, parametric tests were used. The $t$-test results showed that scores for clients' complaints and concerns $(51.5 \pm 8.6)$ reported by the participants were significantly lower relative to those observed for partners' complaints and concerns $(55.2 \pm 7.6 ; t(68)=4.36$, $p<0.001)$.

The results of the Wilcoxon signed-rank tests showed that scores for partners' complaints and concerns were significantly higher, relative to those observed for clients' complaints and concerns, for seven items including difficulty balancing work and treatment, envying people with children, and partners' failure to cooperate with treatment $(p<0.001)$. In contrast, clients' complaint and concern scores were significantly higher, relative to those observed for partners, for only one item: concern regarding the physical health of the partner receiving treatment $(p<0.01)$.

\subsection{Factors Related to Nursing Practice and Perceptions of Nursing for Couples That Included a Partner with Male Infertility}

The results of the Wilcoxon signed-rank test examining factors related to nursing practice and perceptions of nursing for couples that included a partner with male infertility are shown in Table 3. Perceptions of nursing differed significantly between clients and partners for three items. Participants reported that asking clients about their desire to have children was more difficult relative to asking partners about this issue. Participants reported that their experience and understanding of partners was greater, relative to that of clients, and they found

Table 3. Differences in nurses' practices and perceptions of nursing for couples that include a partner with male infertility, between clients and partners $(\mathrm{N}=69)$.

\begin{tabular}{|c|c|c|c|c|c|c|c|c|c|c|}
\hline \multirow{2}{*}{ Item } & \multicolumn{4}{|c|}{ To clients } & \multicolumn{4}{|c|}{ To partners } & \multirow{2}{*}{\multicolumn{2}{|c|}{$p$-value }} \\
\hline & Mean & $\mathrm{SD}$ & Median & Range & Mean & $\mathrm{SD}$ & Median & Range & & \\
\hline Perceptions of nursing & & & & & & & & & & \\
\hline Difficult to discuss sexual matters (reverse scoring) & 2.7 & 0.896 & $\begin{array}{c}3 \\
\end{array}$ & $(1-5)$ & 2.1 & 0.8 & $\begin{array}{r}2 \\
\\
\end{array}$ & $(1-5)$ & 0.001 & $* * *$ \\
\hline Has experience & 2.8 & 1.1 & $\begin{array}{l}3 \\
\llcorner\end{array}$ & $(1-5)$ & 3.4 & 1.0 & $\begin{array}{r}4 \\
\\
\end{array}$ & $(1-5)$ & 0.001 & $* * *$ \\
\hline Understands psychological factors & 3.0 & 0.8 & $\begin{array}{l}3 \\
\end{array}$ & $(1-4)$ & 3.4 & 0.7 & $\begin{array}{r}3 \\
\end{array}$ & $(1-5)$ & 0.001 & $* * *$ \\
\hline Asks about desire to have children and hopes for children & 3.2 & 1.2 & $\begin{array}{l}3 \\
\llcorner\end{array}$ & $(1-5)$ & 3.6 & 1.1 & $\begin{array}{r}4 \\
\underset{0}{\longrightarrow}\end{array}$ & $(1-5)$ & 0.003 & $* *$ \\
\hline Asks about thoughts and feelings towards their partner & 3.4 & 1.1 & 4 & $(1-5)$ & 3.6 & 1.1 & $\begin{array}{l}4 \\
0\end{array}$ & $(1-5)$ & 0.036 & * \\
\hline
\end{tabular}

${ }^{* * *} \mathrm{p}<0.001,{ }^{* *} \mathrm{p}<0.01,{ }^{*} \mathrm{p}<0.05$, Wilcoxon signed-rank test. 
partners easier to deal with. Significant differences in nursing practice were observed for two items. Similar to perception, participants reported that the number of questions they asked partners was higher relative to that of questions they asked clients.

The results regarding differences in nursing practice and nurses' perceptions of nursing according to their attributes are shown in Table 4. Perceptions of nursing differed according to the availability of opportunities to provide physical care $(F(2,65)=8.51, p<0.001)$, whether nurses worked at an infertility department or reproductive medicine center $(F(2,62)=5.11, p<0.01)$, and whether couples attended consultations together or separately $(F(3,62)=3.32$, $p<0.05)$.

Nursing practice differed according to age (55-64 years; $F(3,62)=3.58, p<$ $0.05)$, the availability of opportunities to provide physical care $(F(2,63)=6.46$, $p<0.01)$ or talk to a urologist $(t(50.90)=3.19, p<0.01)$, whether nurses worked at an infertility department or reproductive medicine center $(F(2,62=$ $5.11, p<0.01)$, the frequency with which nurses met with clients $(F(2,62)=$ $5.99, p<0.01)$, and the number of consultations provided $(F(3,61)=8.08, p<$ $0.001)$

The number of years of nursing experience was positively correlated with scores for perceptions of nursing $(r=0.25)$ and the number of years of infertility nursing experience was positively correlated with scores for nursing practice $(r=0.27)$.

\section{Discussion}

Participants reported that psychological burden and problems with partners were more serious for partners than they were for clients, and clients' concern regarding partners' physical health while receiving treatment was greater relative to partners' concern regarding clients' physical health while receiving treatment. This suggests that clients with male infertility had told the nurses that they worried about their wives' treatment.

\subsection{Interaction between Nurses and Urologists and Male Infertility Clients}

Participants' mean duration of infertility nursing experience was 12 years, which suggests that they had gained between 7 and 9 years of experience following qualification. Many of the participants were middle-aged, and approximately $90 \%$ had undertaken classes on the provision of nursing care for clients with male infertility. Most participants were full-time nurses in a reproductive medicine center or the outpatient section of an infertility department at a clinic or hospital. Reproductive medicine specialists were available full and part time in urology departments in $7 \%$ and $28 \%$ of facilities, respectively. Consistent with these proportions, the number of participants who lacked regular opportunities to talk to a urologist was higher relative to that of participants who had such opportunities. These findings indicated that approximately $35 \%$ of affiliated facilities employed 
Table 4. Differences in nursing practice and perceptions of nursing for couples that included a partner with male infertility according to participants' attributes $(\mathrm{N}=69)$.

\begin{tabular}{|c|c|c|c|c|c|c|c|c|}
\hline \multirow{2}{*}{ Subject attributes } & \multicolumn{4}{|c|}{ Perceptions of nursing } & \multicolumn{4}{|c|}{ Nursing practices } \\
\hline & $\mathrm{n}$ & Mean & & SD & $\mathrm{n}$ & Mean & & SD \\
\hline Overall & 69 & 56.4 & \pm & 8.4 & 69 & 51.5 & \pm & 8.6 \\
\hline Age & & $\mathrm{F}(3,64)=1.839$ & $\mathrm{P}=$ & 0.149 & & $F(3,62)=3.583^{\star}$ & & 0.019 \\
\hline 25 to 34 years & 4 & 51.7 & \pm & 4.7 & 4 & 47.8 & \pm & 12.2 \\
\hline 35 to 44 years & 20 & 54.0 & \pm & 6.6 & 20 & 50.2 & \pm & $11.7 \sqsupset^{*}$ \\
\hline 45 to 54 years & 40 & 57.3 & \pm & 9.0 & 38 & 56.0 & \pm & 9.8 \\
\hline 55 to 64 years & 4 & 62.3 & \pm & 10.2 & 4 & 66.3 & \pm & 6.9 \\
\hline Opportunities to provide physical care & & $\mathrm{F}(2,65)=8.510^{* *}$ & & 0.001 & & $\mathrm{~F}(2,63)=6.463^{\star \star}$ & & 0.003 \\
\hline Yes & 26 & 61.2 & \pm & $6.97^{* *}$ & 26 & 60.1 & \pm & $8.1 \boldsymbol{f}^{* *}$ \\
\hline None & 40 & 53.8 & \pm & $8.0]$ & 40 & 51.8 & \pm & $11.7]$ \\
\hline I don't know & 2 & 49.5 & \pm & 3.5 & 2 & 42.0 & \pm & 1.4 \\
\hline Opportunities to talk to a urologist & & $t(63)=1.92$ & & 0.059 & & $\mathrm{t}(50.90)=3.19^{* *}$ & & 0.002 \\
\hline Yes & 33 & 58.8 & \pm & 8.2 & 32 & 59.1 & \pm & $8.0]^{* *}$ \\
\hline None & 32 & 54.8 & \pm & 8.1 & 31 & 50.7 & \pm & $12.5]$ \\
\hline Post & & $F(2,62)=5.110^{\star *}$ & & 0.009 & & $\mathrm{~F}(2,60)=5.047^{\star \star}$ & & 0.009 \\
\hline Obstetrics and gynecology & 22 & 52.7 & \pm & $8.07^{*}$ & 21 & 51.8 & \pm & 10.4 \\
\hline Infertility department or reproductive medicine center & 40 & 59.0 & \pm & $8.1\rfloor$ & 39 & 57.7 & \pm & $10.87^{*}$ \\
\hline Other department & 3 & 51.0 & \pm & 1.7 & 3 & 43.0 & \pm & 6.8 \\
\hline Meeting with male patients & & $\mathrm{F}(2,64)=2.429$ & $\mathrm{P}=$ & 0.096 & & $\mathrm{~F}(2,62)=5.994^{\star *}$ & & 0.004 \\
\hline Very rarely & 14 & 52.1 & & 3.9 & 13 & 46.0 & & $117^{* *}$ \\
\hline Occasionally & 33 & 57.5 & & 10.4 & 33 & 57.3 & & 10.4 \\
\hline Almost everyday & 20 & 57.7 & & 5.7 & 19 & 56.7 & & $10.0\rfloor *$ \\
\hline Number of consultations & & $\mathrm{F}(3,63)=2.098$ & & 0.109 & & $\mathrm{~F}(3,61)=8.078^{* * *}$ & & 0.001 \\
\hline 0 & 2 & 52.0 & \pm & 0.0 & 2 & 40.5 & \pm & $0.77^{*}$ \\
\hline 1 to 10 & 31 & 54.3 & \pm & 8.4 & 30 & 50.1 & \pm & 10.5 *** \\
\hline 11 to 20 & 14 & 56.8 & \pm & 7.0 & 14 & 54.6 & \pm & 10.4 \\
\hline 21 or more & 20 & 59.8 & \pm & 8.5 & 19 & 62.8 & \pm & $8.1 \rrbracket$ \\
\hline Consulter & & $F(3,62)=3.318^{*}$ & $\mathrm{P}=$ & 0.026 & & $F(3,60)=1.719$ & & 0.172 \\
\hline Client & 4 & 50.8 & \pm & 5.5 & 4 & 47.8 & \pm & 7.9 \\
\hline Partner & 42 & 55.9 & \pm & 8.1 & 41 & 54.3 & \pm & 11.5 \\
\hline Couple & 18 & 60.2 & \pm & 9.2 & 19 & 58.2 & \pm & 10.3 \\
\hline Other & 2 & 44.5 & \pm & 3.5 & 2 & 45.0 & \pm & 4.2 \\
\hline
\end{tabular}

T-tests were performed on groups of two, and one-way analysis of variance and Tukey's multiple comparison tests were performed on groups of three or more. ${ }^{*} \mathrm{p}<0.05,{ }^{* *} \mathrm{p}<0.01,{ }^{* * *} \mathrm{p}<0.001$. 
either a full-time or part-time reproductive medicine specialist in their urology departments, suggesting that they provided thorough care in terms of the scale of the treatment provided and the treatment system, in addition to employing a certified infertility nurse.

Most participants met with clients with male infertility for consultations occasionally and lacked opportunities to provide physical care. The number of consultations peaked at two frequencies: At approximately one case per month and approximately two cases per month. Client's partners attended consultations more frequently relative to clients, who rarely initiated consultations. This finding indicates that nurses did not interact with clients often on a regular basis, and there was some variance in the frequency of consultations. Although they accounted for only approximately $6 \%$ of consultations, some participants reported consultations mainly with clients rather than their partners. Through word of mouth, people could have heard that these nurses were easy to consult or provided good results in previous consultations.

\subsection{Differences in Complaints and Concerns between Clients and Partners, Reported by Nurses}

Clients' complaints and concerns involved psychological burden, lack of knowledge and information, and problems with their partners. Most nurses reported that psychological burden and problems with partners were more serious issues for partners than they were for clients. In contrast, concern regarding the physical health of the partner receiving treatment, which resulted from lack of knowledge and information, was a more serious concern for clients than it was for partners. In a study that focused on patients, women visited hospitals and required medication more often, relative to men, even when their male partners were the main cause of the infertility, and exhibited high stress levels [6]. Nurses reported this phenomenon based on what they had witnessed in practice. It is likely that nurses often hear concerns about partners (wives) from clients (husbands). In a study examining the perspectives of certified infertility nurses, Baba [7] found that clients expected the following of nurses in their interactions with couples that included a partner with male infertility: special consideration when explaining results, checking acceptance of the infertility, helping clients to express their emotion, aiding in the decision-making process for treatment selection, and focusing on the couple's relationship. These findings demonstrate the importance of focusing on the complaints and concerns of male infertility clients and their partners.

\subsection{Factors Related to Nursing Practice and Nurses' Perceptions of Nursing for Couples That Included a Partner with Male Infertility}

Which factors are associated with nursing practice and perceptions of nursing? Nurses' perceptions of clients and partners differed according to their experiences with them, levels of understanding of psychological factors, and ease in talking 


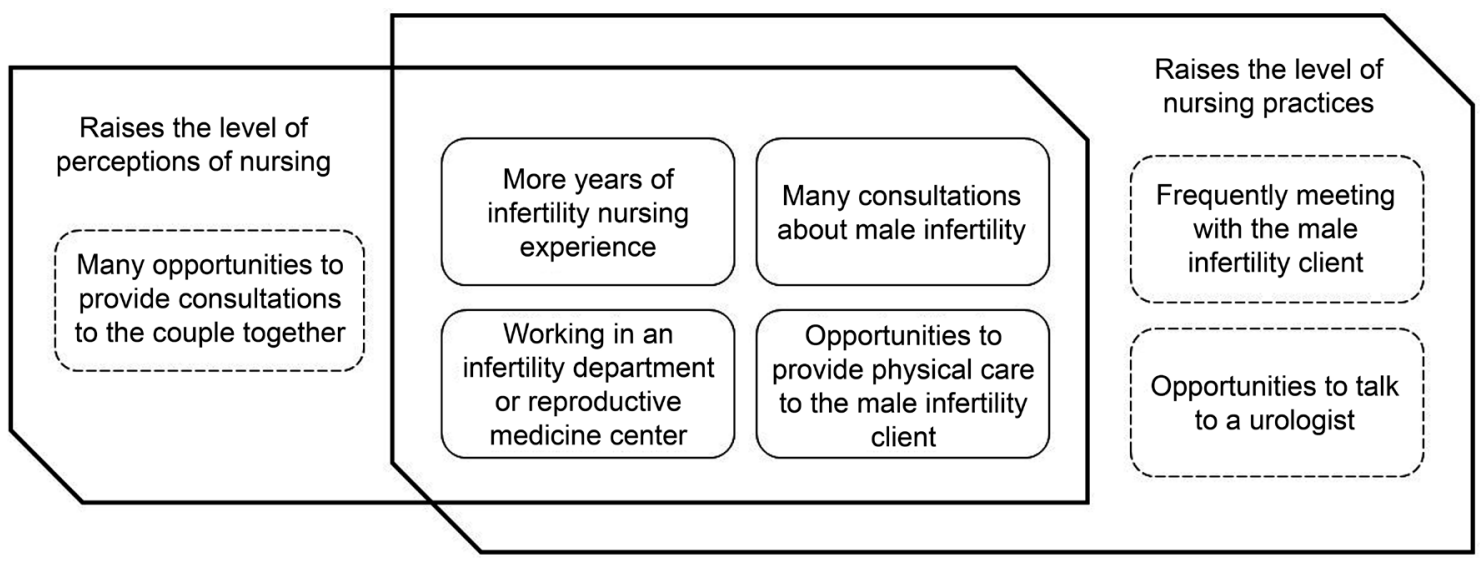

Figure 2. Factors that enhance nursing practice and nurses' perceptions of nursing for couples with male infertility.

about the desire to have children and other issues, and they were more accustomed to providing nursing care to partners rather than clients. In addition, years of experience was an individual background factor. In particular, longer durations of infertility nursing experience were associated with nurses' being more accustomed to providing nursing care and being more conscious of their professional role for couples that included a partner with male infertility. As workplace background factors, working in an infertility department or reproductive medicine center, providing a high number of consultations, and having opportunities to provide physical care were associated with higher scores for nursing practice and perceptions of nursing. Couples' attendance at consultations together was also associated with increased scores for perceptions of nursing. Meeting with male patients frequently and having opportunities to talk to a urologist were associated with higher scores for nursing practice. The factors that promoted nursing for couples that included a partner with male infertility were based on these findings and are summarized in Figure 2; however, they have not been verified. Nursing practice for couples that include a partner with male infertility is established based on meetings with clients, who constitute the target population, and discussions with urologists, who are responsible for client treatment. This could be considered the natural course of development for nursing practice.

Treatment and support systems for couples that include a partner with male infertility are currently insufficient, and an increase in the number of facilities that provide male infertility outpatient care is required to enhance nurses' nursing practice and perceptions of nursing for this population.

\section{Acknowledgements}

The authors would like to express their heartfelt gratitude to everyone who participated in the study. This study was conducted as a part of shared research for a national survey on male infertility, with the assistance of the Ministry of Health, Labour and Welfare (head researcher: Yasushi Yumura). The results were presented at the Japanese Society of Fertility Nursing 14th Research Conference 
and the 61st Annual Meeting of the Japan Society for Reproductive Medicine.

We would like to thank Editage (http://www.editage.jp/) for English language edting.

\section{Conflicts of Interest}

The authors have no conflicts of interest to declare.

\section{Disclosures}

\section{Human Rights Statements and Informed Consent}

All procedures were followed in accordance with the ethical standards of the responsible committees for human experimentation (institutional and national) and the 1964 Helsinki Declaration and later amendments. Informed consent was obtained from all patients.

\section{Animal Studies}

No studies with animals were performed by the authors in preparation of this manuscript.

\section{Approval by Ethics Committee}

The protocol for the research project was approved by the Yokohama City University Ethics Committee.

\section{References}

[1] Japan Society Reproductive Medicine, Ed. (2014) Essential Knowledge of Reproductive Medicine. Kyorin-sha, 52. (In Japanese).

[2] Nachtigall, R.D., Becker, G. and Wozny, M. (1992) The Effects of Gender-Specific Diagnosis on Men's and Women's Response to Infertility. Fertility and Sterility, 57, 113-121. https://doi.org/10.1016/S0015-0282(16)54786-4

[3] Beutel, M,, Kupfer, J., Kirchmeyer, P., Kehde, S., Köhn, F. M., Schroeder-Printzen, I., Gips, H., Herrero, H.J. and Weidner, W. (1999) Treatment-Related Stresses and Depression in Couples Undergoing Assisted Reproductive Treatment by IVF or ICSI. Andrologia, 31, 27-35. https://doi.org/10.1111/j.1439-0272.1999.tb02839.x

[4] Ozawa, M., Yamaguchi, T., Tsuchida, A., Hosoya, I., Takahashi, S., Sumitomo, S., Tsuchiya, S. and Kikuchi, Y. (2012) Nurses' Experiences Involving Relationships with Men Receiving Male Infertility Treatment during Short Term Hospital Admission: Through Focus Group Interview. Japanese Journal of Nursing - Maternity Nursing, 42, 88-91. (In Japanese).

[5] Endo, T., Watanabe, H. and Ogawa, S. (2009) Study of the Role and Scope of Certified Nursing in Infertility Nursing. Journal of Japanese Society of Fertility Nursing, 6, 65-71. (In Japanese).

[6] European Society of Human Reproduction and Embryology Guideline 2015. Routine Psychosocial Care in Infertility and Medically Assisted Reproduction-A Guide for Fertility Staff. https://www.eshre.eu/Guidelines-and-Legal.aspx

[7] Baba, M. (2010) Consideration of Care for Patients with Male Infertility through Certified Infertility Nursing Practice. Urological Nursing, 15, 75-78. (In Japanese). 